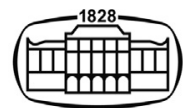

AKADÉMIAI KIADÓ

Acta Chromatographica

33 (2021) 1, 3-10

DOl:

$10.1556 / 1326.2020 .00696$

(C) 2020 The Authors

ORIGINAL RESEARCH PAPER

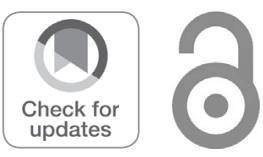

\title{
Separation and quantification of nine bioactive compounds in traditional Unani formulations by High Performance Liquid Chromatography- Photodiode Array Detector
}

Y.T. KAMAL ${ }^{1 *}$ (D), SAYEED AHMAD ${ }^{2}$, NANJAIAN MAHADEVAN ${ }^{1}$, PRAWEZ ALAM ${ }^{3}$, SHAHANA SALAM ${ }^{4}$, YAHYA I ASIRI ${ }^{5}$, ABDULLATIF BIN MUHSINAH ${ }^{1}$ and ABDULRHMAN ALSAYARI ${ }^{1}$

${ }^{1}$ Department of Pharmacognosy, College of Pharmacy, King Khalid University, 61441, Abha, Kingdom of Saudi Arabia

${ }^{2}$ Department of Pharmacognosy and Phytochemistry, Bioactive Natural Product Laboratory, Faculty of Pharmacy, Jamia Hamdard, New Delhi, India

${ }^{3}$ Department of Pharmacognosy, College of Pharmacy, Prince Sattam Bin Abdulaziz University, P.O. Box 173, 11942, Al-Kharj, Kingdom of Saudi Arabia

${ }^{4}$ Department of Pharmaceutical Chemistry, College of Pharmacy, Prince Sattam Bin Abdulaziz University, P.O. Box 173, 11942, Al-Kharj, Kingdom of Saudi Arabia

${ }^{5}$ Department of Pharmacology, College of Pharmacy, King Khalid University, 61441, Abha, Kingdom of Saudi Arabia

Received: August 30, 2019 - Accepted: February 19, 2020

Published online: August 28, 2020

\begin{abstract}
A new High Performance Liquid Chromatography-Photodiode Array Detector (HPLC-PDA) method has been developed for the chromatographic separation and simultaneous quantitative determination of nine bioactive compounds, i.e. four phenolic (gallic acid, ellagic acid, chebulinic acid, and tannic acid), two flavanoids (rutin and quercetin), two anthraquinones (sennoside A and B) and one oxygenated hydrocarbon (vitamin C) in a well-known Unani polyherbal formulation namely Itrifal's. Separation was accomplished on a C18 LiChrospher 100 column $(5 \mu \mathrm{m}, 250 \times 4.6 \mathrm{~mm})$ with a gradient elution and recorded at $254 \mathrm{~nm}$. The results demonstrated that the proposed method is reproducible, accurate, economic, and suitable for the quality control of traditional polyherbal Unani formulations containing complex compounds with different structures such as Itrifals.
\end{abstract}

\section{KEYWORDS}

HPLC-PDA, quality control, polyherbal formulation, simultaneous determination

\section{INTRODUCTION}

The use of herbal drugs for the prevention and treatment of various health ailments has been in practice from time immemorial. Generally, it is believed that the risk associated with herbal drugs is very less, but reports on serious reactions are indicating to the need for development of effective marker systems for isolation and identification of the individual components. Standardisation, stability and quality control for herbal drugs are feasible, but difficult to accomplish [1]. The present study attempts to develop a multi-component High Performance Liquid Chromatography (HPLC) assay method which will help in the quality control of herbal formulations. 
<smiles>O=C(O)c1cc(O)c(O)c(O)c1</smiles>

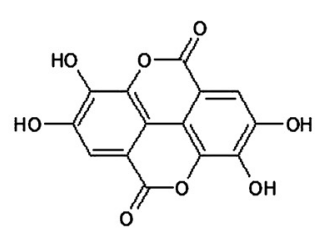

Ellagic acid

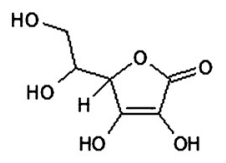

Ascorbic acid<smiles>O=C1c2c(O)cc(O)cc2OC(c2ccc(O)c(O)c2)C1O</smiles><smiles>COc1cccc(C2c3cccc(OC)c3C(=O)c3c(OC)cc(O)cc32)c1C(=O)O</smiles>

Sennoside B

Rutin<smiles>COc1cccc(C2c3cccc(OC)c3C(=O)c3c(O)cc(O)cc3C2c2ccc(O)cc2O)c1O</smiles>

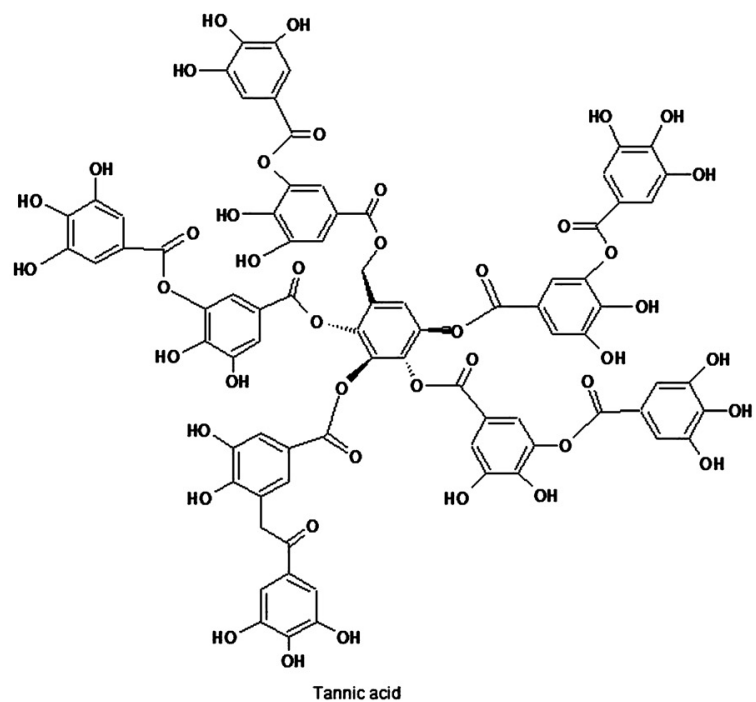

Fig. 1 Chemical structure of all nine bioactive compounds selected for analysis

It is believed that the therapeutic efficacy of traditional Unani multi-herbal formulations is integrative results of multiple bioactive components. These multiple constituents in the herbs/formulations may work 'synergistically' and give the optimum therapeutic effects [2]. Therefore, simultaneous determination of the biologically active components is necessary for the quality control of these types of formulations.

According to the Unani system, Itrifal or Trifaloon is actually the name of a herbal preparation of three different types of fruits i.e. Halela (Terminalia chebula), Balela (Terminalia belerica), Amla (Emblica officinalis). Itrifals are proven for its anti-oxidant activities; most generally it's used as an overall body tonic, thought to be effective in cleansing and detoxifying the system [3]. Additionally, some other ingredients may be added to the base formulation, 'Itrifal' and they are named like Itrifal-e-Aftimoon (IA) and Itrifale-Badiyan (IB), which were selected for the present study. The IA composed of twelve crude drugs namely, T. chebula
(15.2\% w/w), T. belerica $(15.2 \% \mathrm{w} / \mathrm{w})$, E. officinalis $(15.2 \%$ $\mathrm{w} / \mathrm{w})$, Operculina turpenthum $(15.2 \% \mathrm{w} / \mathrm{w})$, Cuscuta epithymum $(7.4 \% \mathrm{w} / \mathrm{w})$, Cassia angustifolia $(7.4 \% \mathrm{w} / \mathrm{w})$, Plumbago zeylanica $(4.5 \% \mathrm{w} / \mathrm{w})$, Polypodium vulgare $(4.5 \%$ $\mathrm{w} / \mathrm{w})$, Lavandula stoechas $(4.5 \% \mathrm{w} / \mathrm{w})$, Rosa damascene (4.5\% w/w), Pimpinella anisum (3\% w/w) and Prunus amygdalus $(3 \% \mathrm{w} / \mathrm{w})$, whereas, IB composed of eight ingredients, namely, T. chebula (7\% w/w), T. belerica $(7 \% \mathrm{w} /$ $\mathrm{w})$, E. officinalis $(7 \% \mathrm{w} / \mathrm{w})$, Vitis vinifera $(7 \% \mathrm{w} / \mathrm{w})$, Rosa damascene $(7 \% \mathrm{w} / \mathrm{w})$, Zataria multiflora $(7 \% \mathrm{w} / \mathrm{w})$, Foeniculum vulgare $(50 \% \mathrm{w} / \mathrm{w})$ and $P$. amygdalus $(7 \% \mathrm{w} / \mathrm{w})$, which are official in National Formulary of Unani Medicines (NFUMs) published by Govt. of India [4]. Five components of both the formulations namely, T. chebula, T. belerica, $E$. officinalis, $R$. damascene, and $P$. amygdalus are common whereas, all the Itrifals should essentially contains $T$. chebula, T. belerica, E. officinalis as an ingredient. Two batches (Batch I and Batch II) for IA and IB were prepared in the laboratory by following the procedure mentioned in NFUM. 

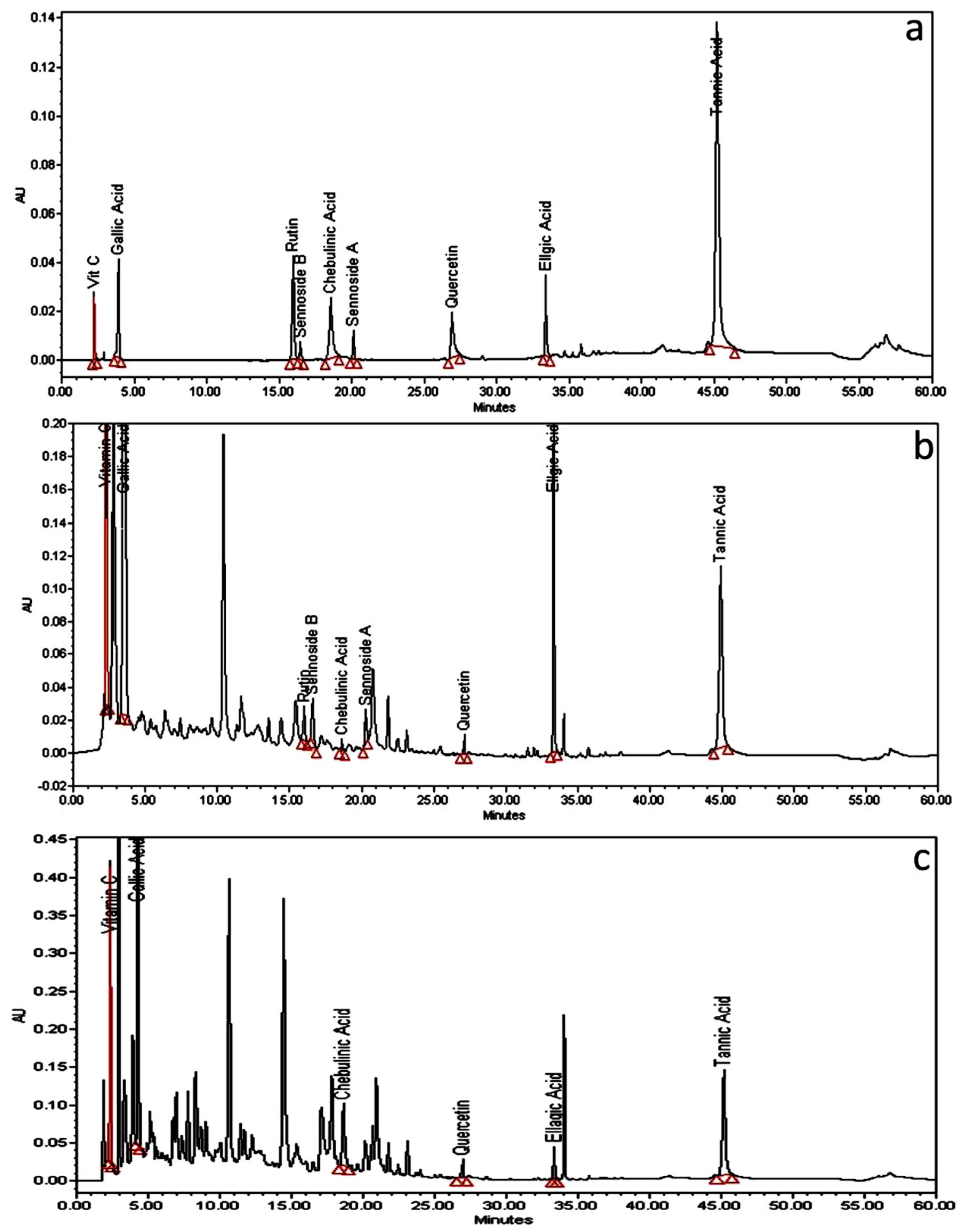

Fig. 2 Representative HPLC-PDA chromatogram at $254 \mathrm{~nm}$ of nine compounds eluting (a) standard (b) Itrifal-e-Aftimoon sample (c) Itrifal-e-Badiyan sample

Concentrated sugar syrup was first prepared by adding $500 \mathrm{~g}$ of sugar in $300 \mathrm{~mL}$ of water and boiling for $15 \mathrm{~min}$ with continuous stirring. The powdered and sieved drugs were added one by one to the sugar syrup with continuous constant stirring.
The major antioxidants are free phenolic acids like ascorbic acid, gallic acid, ellagic acid, chebulinic acid, and tannic acid as well as free flavonoids like rutin and quercetin forms the basis of bioactivity of these Itrifal formulations [5]. The anthraquinone glycosides like sennoside A and B were 
Table 1. Linear relationships between peak area and sample concentration

\begin{tabular}{|c|c|c|c|c|c|c|c|}
\hline Compound & $\begin{array}{l}\text { Calibration } \\
\text { curve }\end{array}$ & $\begin{array}{l}\text { Linear range } \\
(\mu \mathrm{g} / \mathrm{mL})\end{array}$ & Slope \pm SD & Intercept $\pm S D$ & $\begin{array}{l}\text { Regression } \\
\text { coefficient }\end{array}$ & $\begin{array}{l}\text { LOD } \\
(\mu \mathrm{g} / \mathrm{mL})\end{array}$ & $\begin{array}{c}\text { LOQ } \\
(\mu \mathrm{g} / \mathrm{mL})\end{array}$ \\
\hline $\begin{array}{l}\text { Ascorbic } \\
\text { acid }\end{array}$ & $\begin{array}{c}y=201.27 x- \\
146.07\end{array}$ & $6.4-320$ & $201.27 \pm 4.8$ & $144.79 \pm 1.20$ & 0.9994 & 1.2 & 5.3 \\
\hline Gallic acid & $\begin{array}{c}y=1154.9 x+ \\
1520.8\end{array}$ & $1.1-474$ & $1154.9 \pm 31.5$ & $1538.05 \pm 24.40$ & 0.9983 & 0.27 & 0.92 \\
\hline Rutin & $\begin{aligned} y= & 458.81 x+ \\
& 6.0875\end{aligned}$ & $1.8-257$ & $461.14 \pm 6.9$ & $6.08 \pm 0.4$ & 0.9993 & 0.44 & 1.2 \\
\hline Sennoside B & $\begin{array}{c}y=36.818 x+ \\
78.931\end{array}$ & $10-350$ & $36.406 \pm 0.97$ & $78.9 \pm 1.60$ & 0.9989 & 4.1 & 10 \\
\hline $\begin{array}{l}\text { Chebulinic } \\
\text { acid }\end{array}$ & $\begin{array}{c}y=172.08 x+ \\
163.97\end{array}$ & $10.6-355.8$ & $172.0 \pm 5.1$ & $167.79 \pm 4.74$ & 0.9996 & 3.2 & 10.1 \\
\hline Sennoside A & $\begin{array}{c}y=109.88 x- \\
2850\end{array}$ & $10-220$ & $109.56 \pm 2.12$ & $2875.7 \pm 31.63$ & 0.9929 & 3.1 & 10.3 \\
\hline Quercetin & $y=112.31 x-$ & $5-346.8$ & $112.3 \pm 2.0$ & $87.5 \pm 0.74$ & 0.9967 & 1.4 & 5 \\
\hline Ellagic acid & $\begin{array}{c}y=473.7 x- \\
838.12\end{array}$ & $2.3-456$ & $477.1 \pm 3.31$ & $841.64 \pm 10.45$ & 0.9995 & 0.85 & 2.2 \\
\hline Tannic acid & $y=332.54 x+$ & $2.8-2000$ & $335.68 \pm 3.29$ & $842.45 \pm 0.5$ & 0.9997 & 0.70 & 2.1 \\
\hline
\end{tabular}

selected as a specific marker for C. angustifolia, which is present in a significant amount in IA.

Literature survey reveals that up to now no methods have been reported on the quantitative analysis for multiple compounds in Itrifal formulations. In most of the previous studies, phenolic, and flavonoid constituents in various herbal samples had been analysed by HPTLC [6], HPLC-CAD [7], HPLC-DAD [8], HPLC-DAD-ESIMS [9], and HPLC-PDA [10] methods with the emphasis on individual components. In addition, most of the methods reported on the quality control of polyherbal formulations deals only with the quantification of one or two components [11]. The HPLC methods reported on the simultaneous quantification of multi component traditional formulation fails to suggest a proper extraction procedure in order to attain the maximum recovery of all the markers. The direct injection of such samples in HPLC will lead to interference of targeted marker components with other moieties present in the sample and the compounds in lower concentrations cannot be detected.

The aim of the study is to develop a simple, reliable and reproducible method on the simultaneous determination of multiple active components present in these commonly used traditional medicines for their quality control as well as to propose an optimised extraction procedure in order to improve the recovery of all nine marker constituents from polyherbal Unani formulations.

\section{EXPERIMENTAL}

\section{Samples, chemicals, solvents and standards}

Three batches of Itrifal-e-Aftiomoon and Itrifal-e-Badiyan were chosen for analysis, batch I was prepared by the ingredients collected from northern part of India (Delhi), whereas batch II was formulated using the ingredients purchased from southern part of India (Hyderabad). Both batches were prepared as per the procedure mentioned in National Formulary of Unani Medicine (NFUM) published by Govt. of India. Batch III was obtained as gift sample from Central Council for Research in Unani Medicines (CCRUM, Hyderabad). All the component drugs of formulations were identified by a botanist of University and same were authenticated by a Pharmacognosist of laboratory. The voucher specimens of all the drugs and formulations have been deposited in Bioactive Natural Product Laboratory of University. Ortho-phosphoric acid $\left(\mathrm{H}_{3} \mathrm{PO}_{4}\right)$ 88\% was purchased from Spectrochem Pvt. Ltd., Mumbai, acetonitrile and methanol were of HPLC grade from Merck Specialities Private Ltd., Mumbai. Milli Q water was used throughout the experiment, which was prepared using Millipore water purification system.

Gallic acid 97\%, ellagic acid 97\%, and tannic Acid 95\% standards were obtained as gift samples from Sami Labs Ltd., Bangalore, (India). Ascorbic acid 99\%, Rutin 98\%, and Quercetin 96\% reference standards were obtained from Sigma Aldrich (USA). Chebulinic acid 95\%, Sennoside A 94\%, and Sennoside B $89 \%$ standards were procured from ChromaDex, India (Bangalore). The chemical structures of all nine components were given in Fig. 1.

\section{Chromatographic conditions and instrumentation}

The analysis was carried out on a Waters Alliance e2695 separating module (Waters Co., MA, USA) using photo diode array detector (Waters 2998) with autosampler and column oven. The instrument was controlled by use of Empower software installed with equipment for data collection and acquisition. Compounds were separated on a C18 reverse phase $(\mathrm{RP})$ column $(250 \times 4.6 \mathrm{~mm}$, particle size $5 \mu \mathrm{m}$, Merck, Germany) maintained at room temperature. 
Table 2. Accuracy study of phenolics, flavonoids and anthraquinones

\begin{tabular}{|c|c|c|c|c|c|}
\hline Compound & $\begin{array}{c}\text { Mean of actual amount } \\
(\mu \mathrm{g} / \mathrm{mL})\end{array}$ & $\begin{array}{l}\text { Mean amount spiked } \\
(\mu \mathrm{g} / \mathrm{mL})\end{array}$ & $\begin{array}{c}\text { Mean recovered amount } \\
(\mu \mathrm{g} / \mathrm{mL})\end{array}$ & Mean \% recovery & $\begin{array}{c}\% \\
\text { RSD }\end{array}$ \\
\hline \multicolumn{6}{|l|}{ Ascorbic acid } \\
\hline 1 & 39.60 & 19.77 & 59.68 & 100.52 & 0.27 \\
\hline 2 & 39.55 & 39.62 & 79.49 & 100.41 & 0.31 \\
\hline 3 & 39.66 & 59.44 & 98.97 & 99.87 & 1.21 \\
\hline \multicolumn{6}{|l|}{ Gallic acid } \\
\hline 1 & 174.4 & 87.88 & 257.29 & 98.10 & 2.33 \\
\hline 2 & 175.0 & 174.2 & 340.82 & 97.6 & 1.01 \\
\hline 3 & 174.9 & 263.15 & 440.67 & 100.6 & 0.67 \\
\hline \multicolumn{6}{|l|}{ Rutin } \\
\hline 1 & 35.27 & 17.68 & 54.88 & 103.65 & 0.56 \\
\hline 2 & 35.42 & 35.87 & 68.80 & 96.51 & 0.33 \\
\hline 3 & 36.11 & 54.11 & 88.32 & 97.9 & 1.12 \\
\hline \multicolumn{6}{|l|}{ Sennoside B } \\
\hline 1 & 10.82 & 5.25 & 17.4 & 108.27 & 0.55 \\
\hline 2 & 10.69 & 10.98 & 21.65 & 99.90 & 0.76 \\
\hline 3 & 10.89 & 16.19 & 27.18 & 100.36 & 0.74 \\
\hline \multicolumn{6}{|c|}{ Chebulinic acid } \\
\hline 1 & 12.43 & 6.27 & 18.54 & 99.18 & 2.11 \\
\hline 2 & 12.46 & 12.56 & 23.70 & 94.36 & 3.56 \\
\hline 3 & 12.51 & 18.82 & 32.96 & 105.21 & 0.56 \\
\hline \multicolumn{6}{|l|}{ Sennoside A } \\
\hline 1 & 17.25 & 8.72 & 26.12 & 100.6 & 0.43 \\
\hline 2 & 17.38 & 17.30 & 34.53 & 99.56 & 0.89 \\
\hline 3 & 17.32 & 24.99 & 42.10 & 99.52 & 1.44 \\
\hline \multicolumn{6}{|l|}{ Quercetin } \\
\hline 1 & 6.82 & 3.54 & 10.73 & 103.59 & 2.51 \\
\hline 2 & 6.69 & 6.81 & 13.55 & 100.40 & 0.34 \\
\hline 3 & 6.49 & 9.66 & 16.51 & 102.27 & 0.92 \\
\hline \multicolumn{6}{|l|}{ Ellagic acid } \\
\hline 1 & 56.32 & 28.11 & 82.20 & 97.36 & 1.30 \\
\hline 2 & 57.11 & 57.77 & 115.44 & 100.49 & 3.93 \\
\hline 3 & 56.81 & 85.76 & 142.13 & 99.69 & 4.44 \\
\hline \multicolumn{6}{|l|}{ Tannic acid } \\
\hline 1 & 1932.1 & 956.2 & 2855.0 & 98.85 & 2.4 \\
\hline 2 & 1911.3 & 1906.6 & 3869.8 & 101.36 & 0.88 \\
\hline 3 & - & - & - & - & \\
\hline
\end{tabular}

The mobile phase consisted of solvent A $(0.05 \%$, v/v solution of orthophosphoric acid) and solvent B (Acetonitrile containing $0.5 \%$ mobile phase $\mathrm{A}$ ) with the elution profile as follows: $0-20 \% \mathrm{~B}$ at $0-10 \mathrm{~min}, 20-22 \% \mathrm{~B}$ at $10-15 \mathrm{~min}, 22-$ $30 \% \mathrm{~B}$ at $15-20 \mathrm{~min}, 30-40 \% \mathrm{~B}$ at $20-25 \mathrm{~min}, 40-50 \% \mathrm{~B}$ at $25-30 \mathrm{~min}, 50-60 \% \mathrm{~B}$ at $30-35 \mathrm{~min}, 60-80 \% \mathrm{~B}$ at $35-60 \mathrm{~min}$ and the re-equilibration time for each gradient elution was $15 \mathrm{~min}$. The flow rate was $1.0 \mathrm{~mL} / \mathrm{min}$; the column was maintained at room temperature.

\section{Sample preparation}

The extraction procedure was optimised prior to preparation of sample for complete recovery of all desired nine components of analysis using different compositions of methanol: water varying time for extraction by sonication, which was monitored using proposed HPLC method. One g each of IA and IB samples (in triplicate) were taken separately from each batch in a $50 \mathrm{~mL}$ conical flask and $25 \mathrm{~mL}$ of solvent (70\% methanol) was added and mixed well. It was sonicated for $40 \mathrm{~min}$ at room temperature and filtered using Whatman filter paper no. 4 (the extraction solvent and time of sonication was optimised and selected after several trials for maximum recovery of all nine components). The filtrate obtained was transferred to a separating funnel $(100 \mathrm{~mL}$ volume) and extracted with $25 \mathrm{~mL}$ of hexane to remove undesired nonpolar compounds. Aqueous methanol extract was dried using rotavapor below $40{ }^{\circ} \mathrm{C}$ and the residues obtained was reconstituted in $10 \mathrm{~mL}$ of solvent i.e. methanol: water $(1: 1, \mathrm{v} / \mathrm{v})$, further transferred to $25 \mathrm{~mL}$ of volumetric flask and make up the volume to obtain a concentration of $40 \mathrm{mg} / \mathrm{mL}$. All the sample solutions were filtered through $0.22 \mu \mathrm{m}$ syringe filter before injecting. 
Table 3. Intra and inter-day variations of the method

\begin{tabular}{|c|c|c|c|c|c|c|c|c|c|}
\hline \multirow[b]{3}{*}{ Compound } & \multirow[b]{3}{*}{ Actual retention time } & \multicolumn{4}{|c|}{$\begin{array}{l}\text { Intra-day precision } \\
\qquad(\% \mathrm{RSD})\end{array}$} & \multicolumn{4}{|c|}{$\begin{array}{c}\text { Inter-day precision } \\
(\% \mathrm{RSD})\end{array}$} \\
\hline & & \multicolumn{2}{|c|}{ Standard } & \multicolumn{2}{|c|}{ Sample } & \multicolumn{2}{|c|}{ Standard } & \multicolumn{2}{|c|}{ Sample } \\
\hline & & $\mathrm{RT}$ & Area & RT & Area & $\mathrm{RT}$ & Area & $\mathrm{RT}$ & Area \\
\hline Ascorbic acid & 2.278 & 1.72 & 0.22 & 1.11 & 2.44 & 2.23 & 0.84 & 2.22 & 1.02 \\
\hline Gallic acid & 3.518 & 1.30 & 0.43 & 0.66 & 1.12 & 0.88 & 0.70 & 1.51 & 0.69 \\
\hline Rutin & 16.002 & 0.83 & 1.22 & 0.44 & 0.44 & 0.97 & 1.77 & 1.37 & 1.07 \\
\hline Sennoside B & 16.591 & 0.66 & 0.87 & 0.45 & 0.78 & 0.74 & 1.64 & 0.89 & 0.59 \\
\hline Chebulinic acid & 18.639 & 0.23 & 1.55 & 1.86 & 0.89 & 1.96 & 0.67 & 1.69 & 0.93 \\
\hline Sennoside A & 20.286 & 0.76 & 3.1 & 0.50 & 0.66 & 1.07 & 0.54 & 2.49 & 0.87 \\
\hline Quercetin & 20.214 & 2.5 & 2.6 & 0.58 & 1.52 & 1.69 & 0.71 & 1.95 & 0.14 \\
\hline Ellagic acid & 33.327 & 0.97 & 0.77 & 0.63 & 1.99 & 0.73 & 0.93 & 2.50 & 1.22 \\
\hline Tannic acid & 44.915 & 1.66 & 0.99 & 2.22 & 2.96 & 0.39 & 0.76 & 1.75 & 0.66 \\
\hline
\end{tabular}

\section{RESULTS AND DISCUSSION}

\section{Optimisation of chromatographic conditions}

Since, the polarity range of the components is very narrow, gradient elution was carried out to separate maximum components of formulation. The mobile phase was selected using different compositions of methanol-water (50:50 and 80:20) and acetonitrile-water (20:80 and 60:40) with some modifiers including orthophosphoric acid, formic acid, acetic acid, phosphate buffer, acetate buffer with different $\mathrm{pH}$ values adjusted using triethyl amine and ammonia, which were investigated under different gradient elution modes. After many trials, excellent separation of all components were achieved on solvent A $(0.05 \%$, v/v solution of orthophosphoric acid) and solvent B (acetonitrile containing $0.5 \%$ mobile phase A), in gradient elution upto 60 min, the representative HPLC-PDA chromatograms of all the nine reference compounds and samples are shown in Fig. 2.

The UV spectra of each analyte was determined independently to get the $\lambda_{\max }$ of all nine components viz.; vitamin $\mathrm{C}$, gallic acid, rutin, sennoside A, chebulinic acid, sennoside B, quercetin, ellagic acid, and tannic acid at 243 , $271,255,267,278,269,255,256$, and $273 \mathrm{~nm}$, respectively. In order to detect all nine components with good sensitivity, $254 \mathrm{~nm}$ wavelength was selected as the detecting wavelength for the analysis.

\section{Optimisation of extraction procedure for sample preparation}

The optimisation of extraction methodology needs to be investigated in order to obtain satisfactory extraction efficiency, which must enables complete extraction of the compounds of interest avoiding chemical modification [12]. In attempt to find the optimum solvent composition and extraction time, different solvent ratios were tried for extraction and the recoveries all nine components at different time intervals were also monitored by the HPLC method. Aqueous methanol was reported to be a suitable solvent for the extraction of phenolic and flavonoid compounds [13-15]. Solubility studies conducted on phenolic and flavonoid compounds showed that the most suitable solvent was methanol-water (70:30). Optimisation of extraction procedure was aimed to maximise the recovery of all nine components. In this study, $70 \%$ methanol in water as a solvent and extraction time of $40 \mathrm{~min}$ by sonication was found to be optimum for the extraction of all the components. So, the optimum extraction time for the samples was set as $40 \mathrm{~min}$ in $70 \%$ methanol in water to extract the poly herbal formulations.

\section{Method validation}

The proposed method was validated as per ICH guidelines [16] for different parameters like linearity, accuracy, precision, limits of detection (LOD) and limits of quantification (LOQ) and robustness similar to the methods reported by laboratory [17-20].

\section{Calibration curves, limits of detection and quantification}

Standard stock solutions of nine reference standards, each of $500 \mu \mathrm{g} / \mathrm{mL}$ concentrations (vitamin $\mathrm{C}$, gallic acid, rutin, sennoside $\mathrm{B}$, chebulinic acid, sennoside $\mathrm{A}$, quercetin, ellagic acid, and tannic acid) were prepared by dissolving them in water:methanol (1:1). The stock solutions were then diluted to different concentrations and working standard solutions were stored at $4{ }^{\circ} \mathrm{C}$ till it was applied on HPLC after filtration using $0.22 \mu \mathrm{m}$ syringe filter before injecting for construction of calibration plots.

The calibration curves were plotted with at least six appropriate concentrations in triplicate in the ranges of 6.4$320,1.1-474,1.8-257,10-350,10.6-355.8,10-220$, 5-346.8, $2.3-456$, and $2.8-2000.0 \mu \mathrm{g} / \mathrm{mL}$ for ascorbic acid, gallic acid, rutin, sennoside $B$, chebulinic acid, sennoside $A$, quercetin, ellagic acid, and tannic acid, respectively.

The lowest diluted solutions of the nine reference compounds in the calibration curves were further diluted to a 
series of concentrations with $50 \%$ methanol for the determinations of LOD and LOQ. The LOD and LOQ under the present chromatographic conditions were determined at a signal-to-noise $(\mathrm{S} / \mathrm{N})$ ratio of 3 and 10 , respectively. Calibration curves, regression equation along with LOD and LOQ for each compound have been shown in Table 1.

\section{Specificity}

The specificity was confirmed by the absence of any endogenous interference at retention times of peaks of interest, which is self-indicative by matching retention times, spectrums and peak purity through PDA.

\section{Precision and accuracy}

Precision of the method was determined by carrying out the intra-day and inter-day variation tests. Inter-day and intra-day precisions were done by preparing and applying three different concentrations of standard in triplicate six times a day and similarly on six different days, respectively. The Relative Standard Deviation (RSD) was taken as a measure of precision (Table 2).

To evaluate the accuracy, the pre-analysed samples were spiked with standard at three different known concentration levels i.e. 50, 100 and $150 \%$ and the mixtures were reanalysed by the proposed method. Average recoveries of investigated targets ranged from $94.36 \%$ to $108.27 \%$, and RSD values were all $<3 \%(n=3)$. From acquired data it was found that the developed method was reliable and accurate for the measurement (Table 3).

\section{Sample analysis}

The HPLC-PDA method was developed and successfully employed for the identification and quantification of nine marker components in three different batches of two traditional poly herbal formulations; Itrifal-e-Aftimoon and Itrifal-e-Badiyan, which are commonly prescribed in Unani System of Medicine (USM). All the samples were analysed according to the optimised extraction procedure described earlier in the section. Identification of the peaks in the sample chromatograms were carried out by comparing retention and PDA spectra of each component. The content of each analyte was calculated from the corresponding calibration curve. The amount of markers $(n=$ 3) present in each formulation were quantified in three different batches were listed in Table 4. The Itrifal-e-Aftimoon samples were identified for the presence of all nine marker components whereas in Itrifal-e-Badiyan, rutin and sennosides were absent. There were no remarkable differences in the quantities of all these components in the three batches analysed in case of both samples.

An increase in demand in the usage of traditional medicine is found worldwide in recent years.

There are many reports available on the standardisation of poly herbal formulations, where bioactive compounds were estimated by HPLC method [21]. By considering this fact in mind, a RP-HPLC method reported here represents

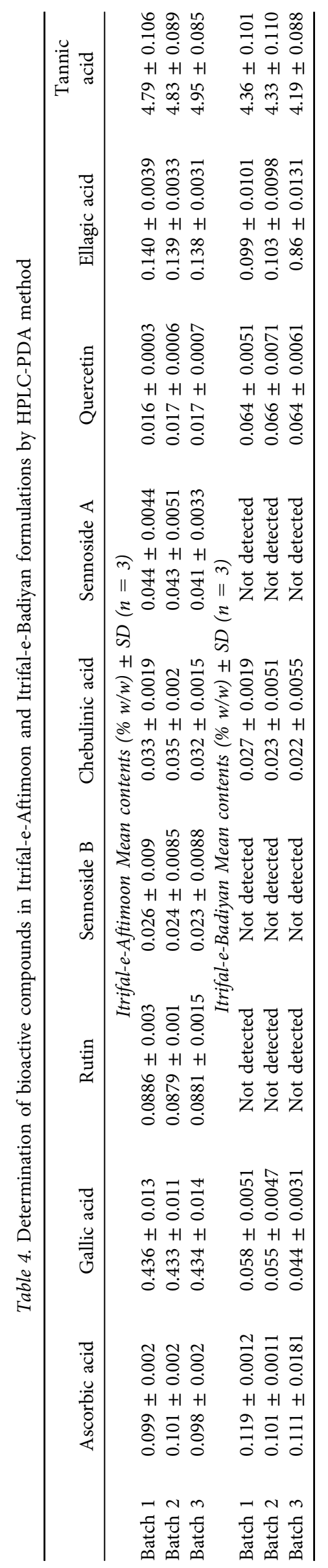


a simple, accurate and rapid technique for simultaneous determination of four phenolics (gallic acid, ellagic acid, chebulinic acid, and tannic acid), two flavonoids (rutin and quercetin), two anthraquinones (sennoside $\mathrm{A}$ and $\mathrm{B}$ ) and one oxygenated hydrocarbon (vitamin C) in Itrifals. This is the first report on the simultaneous determination these nine markers in a traditional Unani polyherbal formulations. The main advantage of the method includes the simplicity of extraction procedure, simultaneous detection and quantification of all these nine bioactive components in a single chromatographic run. The quantification limits were found to be low enough for the successful employment of the method in different polyherbal formulations which contains these components in very minute quantities. The efficiency of the method was evaluated from conducting recovery experiments and the results found to be promising, which indicates that the method can be executed successively in various multi component herbal formulations with high accuracy and precision. The linearity experiments conducted proved that the method can be applied for the samples which contain these components in a wide range.

\section{CONCLUSION}

In conclusion, the proposed method is useful as a reliable, fast and effective tool for the quality control as well as standardisation of different formulations, especially traditional polyherbal formulations like Itrifals and Triphala of Unani and Ayurvedic Systems of medicines. This simple multi-component assay method will be helpful in quality control of a large no of traditional formulations and can also be extended for the pharmacological, biopharmaceutical and pharmacokinetic studies.

\section{REFERENCES}

1. Sahoo, N.; Manchikanti, P.; Dey, S. Fitoterapia 2010, 81, 462-71.
2. Xiao-Jie, T. B.; Qing Li, B.; Xiao-Hui, C.; Zhi-Wei, W.; Zheng-Yuan, S.; Kai-Shun, B. B.; Ying, J. J. Pharm. Biomed. Anal. 2008, 47, 847-53.

3. Koneru, K.; Satynarayana, S.; Mukkanti, K.; Khan, K. A. Am. J. Drug Disc. Dev. 2011, 1, 1-8.

4. Anonymous. National Formulary of Unani Medicine, Ministry of Health and Family Welfare, Department of AYUSH, Govt. of India, New Delhi, 2006, Part. I, vol. II, 191.

5. Kaur, S.; Michael, H.; Arora, S.; Harkonen, P. L.; Kumar, S. J. Ethnopharmacol. 2005, 97, 15-20.

6. Ragazzi, E.; Veronesea, G. J. Chromatogr. A 1973, 77, 369-75.

7. Jandera, P.; Skeríkova, V.; Rehova, L.; Hajek, T.; Baldrianova, L.; Skopova, G.; Kellner, V.; Horna, A. J. Sep. Sci. 2005, 28, 1005-22.

8. Markowski, J.; Płocharski, W. J. Fruit Ornament. Plant Res. 2006, $14,133-42$.

9. Fang, Z.; Zhang, M.; Wang, L. Food Chem. 2007, 100, 845-52.

10. Revilla, E.; Ryan, J. M. J. Chromatogr. A 2000, 881, 461-9.

11. Ahmad, W.; Zaidi, S. M. A.; Mujeeb, M.; Ansari, S. H.; Ahmad, S. J. Chromatogr. Sci. 2014, 52, 911-8.

12. Hong-jiang, C.; Xiang, L.; Jian-wei, C.; Sheng, G.; Bao-chang, C. J. Pharm. Biomed. Anal. 2010, 51, 1142.

13. Georg, M. W.; Dietmar, R. K.; Reinhold, C. Food Chem. 2009, 115, 758-65.

14. Ranjith, A.; Sarin, K. K.; Arumughan, C. J. Pharm. Biomed. Anal. 2008, 47, 31-8.

15. Lillian, B.; Montserrat, D.; Isabel, C. F. R. F.; Ana, M. C.; Celestino, S. B. Food Chem. 2011, 127, 169-73.

16. International Conference on Harmonization (ICH) of Technical Requirements for the Registration of Pharmaceuticals for Human Use, Validation of Analytical Procedures: Methodology, adopted in 1996, Geneva.

17. Ahmad, S.; Rizwan, M.; Parveen, R.; Mujeeb, M.; Aquil, M. Chromatographia, 2008, 67, 441-7.

18. Ansari, M. J.; Ahmad, S.; Kohli, K.; Ali, J.; Khar, R. K. J. Pharm. Biomed. Anal. 2005, 39, 132-8.

19. Alam, P.; Ali, M.; Singh, R.; Madhurima; Ahmad, S.; Shakeel, F. J. Chromatogr. Sci. 2009, 47, 910-3.

20. Parveen, R.; Baboota, S.; Ali, J.; Ahuja, A.; Ahmad, S. Biomed. Chromatogr. 2010, 24, 639-47.

21. Mishra, A.; Mishra, A. K.; Tiwari, O. P.; Jha, S. J. Young Pharm. 2013, 5, 77-82. 